\title{
Erratum to: Complications Due to Medicaments
}

\author{
Zuhair Alkhatib and Rashid El Abed
}

\section{Erratum to:}

Chapter 7 in: P. Jain (ed.), Common Complications in Endodontics, https://doi.org/10.1007/978-3-319-60997-3_7

The original version of Chapter 7 was inadvertently published without the source line for Figure 7.3 on page 155.

\section{The updated figure caption should read as:}

Open-end needles vs. side-vent needles (Boutsioukis C et al. Journal of Endodontics 2010)

\footnotetext{
The updated original online version for this chapter can be found at https://doi.org/10.1007/978-3-319-60997-3_7
}

Z. Alkhatib, B.D.S., M.S. ( $\square) \cdot$ R. El Abed MBR University of Medicine and Health Sciences, Dubai, UAE e-mail: zzk321@gmail.com 